\title{
Resistencia, auge y contrarrevolución. Un análisis cuantitativo de las luchas estudiantiles platenses entre 1966 y 1976
}

\author{
Resistance, boom and counterrevolution. A quantitative analysis of the student \\ struggles of La Plata between 1966 and 1976
}

\author{
iD Juan Sebastián Califa \\ jscalifa@hotmail.com \\ Instituto de Historia Argentina y Americana Dr. \\ Emilio Ravignani. Universidad de Buenos Aires - \\ CONICET, Argentina

\section{Mariano Millán} \\ marianomillan82@gmail.com \\ Instituto de Historia Argentina y Americana Dr. \\ Emilio Ravignani. Universidad de Buenos Aires - \\ CONICET, Argentina
}

Recepción: 02 Julio 2021

Aprobación: 20 Septiembre 2021

Publicación: 01 Noviembre 2021

Cita sugerida: Califa, J.S y Millán, M.(2021).

Resistencia, auge y contrarrevolución. Un análisis cuantitativo de las luchas estudiantiles platenses entre 1966 y 1976. Anuario del Instituto de Historia Argentina, 21(2), e152.

https://doi.org/10.24215/2314257Xe152

\begin{abstract}
Resumen: En este artículo se abordan las luchas del movimiento estudiantil de la Universidad Nacional de La Plata entre los golpes de Estado de 1966 y 1976. Para ello analizamos los enfrentamientos sociales en los que participaron estudiantes en tanto tales a partir de las formas de acción, las corrientes involucradas, los reclamos esgrimidos, los escenarios de lucha y las alianzas desarrolladas. Mediante una metodología cuantitativa localizamos los ciclos de conflictividad platense y abordamos su vínculo con los sucesos nacionales. La exposición cuantitativa de este trabajo se asienta en la codificación de una base de datos de hechos de lucha estudiantil confeccionada con periódicos, mientras que las lecturas de los datos interpelan la copiosa literatura científica sobre el tema.
\end{abstract}

Palabras clave: Enfrentamientos sociales, Movimiento estudiantil, La Plata, Intervención universitaria.

\begin{abstract}
This article addresses the struggles of the student movement of the National University of La Plata between the coups d'état of 1966 and 1976. For this, we analyze the social confrontations in which students participated as such based on the forms of action, the currents involved, the claims made, the scenarios of struggle and the alliances developed. Through a quantitative methodology, we locate the cycles of conflict in La Plata and address their link with national events. The quantitative exposition of this work is based on the codification of a database of student struggle facts made with newspapers, while the readings of the data challenge the copious scientific literature on the subject.
\end{abstract}

Keywords: Social confrontations, Student movement, La Plata, University intervention.

\section{La Plata, ciudad universitaria}

En este artículo ofrecemos un análisis cuantitativo de las luchas estudiantiles en la Universidad Nacional de La Plata (UNLP) entre los golpes de Estado de 1966 y 1976. Nuestras coordenadas temporales comienzan con la instauración de la autodenominada "Revolución Argentina", inicialmente presidida por Juan Carlos 
Onganía y concluida siete años después tras un ciclo de combates sociales protagonizados por el movimiento obrero y el movimiento estudiantil, y finalizan con la imposición de la última dictadura cívico-militar.

Durante aquella década La Plata se constituyó como un escenario característico de lucha social. Fundada a fines del siglo XIX, pronto se transformó en centro de una pujante actividad fabril. Durante 1961, en tiempos del desarrollismo, la gobernación bonaerense impulsó el "Plan Urbis" (Romá, 2012, p. 167), un proyecto inconcluso de obras viales que dio nuevos bríos a la industrialización en la zona. En la rivera del Río de la Plata convivían la refinería petrolera de Ensenada, la Destilería de YPF, varias grandes plantas siderúrgicas, metalúrgicas y químicas, el Astillero Río Santiago y numerosos establecimientos de menor escala. Para 1970 el Gran La Plata (La Plata, Berisso y Ensenada) constituía el cuarto conglomerado urbano del país, con medio millón de habitantes.

Pese a lo señalado, se estima que el 62,5\% de la mano de obra de la zona se empleaba en el sector "comercio y servicios", siendo el $42 \%$ estatal, una incidencia que se explica por el hecho de que La Plata era (y es) sede de la administración pública provincial. Este factor, junto a la presencia de la universidad, impactaron en la dinámica del mercado inmobiliario, la construcción y/o el comercio minorista, entre otras ramas (Nava, 2017, p. 70 y p. 71).

En La Plata, como en el resto del país, la conflictividad obrera acreció a fines de los '60. Un caso paradigmático fue la huelga petrolera de Ensenada de 1968 (Dawyd, 2011). En paralelo, la conmemoración del cincuentenario de la Reforma Universitaria dinamizó una segunda oleada de respuestas contra la intervención de las universidades (Bonavena y Califa, 2018). Estos conflictos sacudieron el ritmo local de la lucha de clases, aunque “Quizá el 'Invierno Caliente’ de 1968 fuera lo más parecido a un 'azo' que tuvo la ciudad, no obstante, en una coyuntura nacional completamente distinta, aún no preparada para que la protesta masiva expresara aquellas percepciones." (Pis Diez, 2019, p. 9) El auge platense posterior, con gran participación de estatales, coexistió con las revueltas de otras ciudades y se integró en un proceso que acabó con la dictadura. No obstante, en la activación obrera local predominaron reclamos corporativos defensivos y formas de acción no disruptivas (Nava, 2017, pp. 106-125).

La capital bonaerense era (y es) también una ciudad universitaria. La pequeña institución provincial fue nacionalizada a principios del siglo XX y para los años '60 reunía la segunda matrícula universitaria de Argentina, con casi 30.000 alumnos (Pérez Lindo, 1985, p. 171).La sociabilidad estudiantil, un aspecto relevante pero no abordado en este trabajo cuantitativo, presentaba una combinación de particularidades. Para muchos jóvenes llegados desde pequeñas urbes, la atmósfera barrial platense resultaba familiar. Sin embargo, la vida en común en las pensiones y los encuentros en bares, como el Astro aledaño a la Facultad de Derecho, donde se trababan amistades, se planeaban aventuras y se discutía política, proporcionaban sensaciones desconocidas. En el centro se imponía el vértigo de las grandes ciudades, amplificado por el día a día en las bulliciosas aulas de la UNLP y los almuerzos en su comedor, habitualmente convertidos en asambleas (por ejemplo, Gatica, 2005, p. 27). Según Pis Diez, las facultades de Humanidades y Ciencias de la Educación y Bellas Artes constituían parte nodal de la red que conectaba la universidad, la cultura juvenil y la militancia partidaria (2018, p. 45). Entrada la década del '70 esta red se amplió al resto de las facultades, incluso a las más pequeñas como el Museo de Ciencias Naturales, donde se estableció una tradición asamblearia. Asimismo, otro rasgo platense es la importancia de los alumnos extranjeros. Entre ellos destacaban los peruanos, muchos reformistas, y varios con trayectorias relevantes para comprender los tránsitos entre izquierda latinoamericana y peronismo, como el grupo Amauta y Jorge Carpio (Ghilini y Pis Diez, 2017).

El movimiento estudiantil de la ciudad tenía una extensa tradición. El primer jalón lo constituyen las protestas y cambios de 1919, inspirados por la Reforma de Córdoba, pero con colores propios (Biagini, 2001; Graciano, 2008). Casi medio siglo después, las coordenadas de la Guerra Fría ganaron incidencia en el proceso de radicalización estudiantil, donde se reconoce como un hito en la lucha "Laica o Libre" en 1956 y 1958 : "El Anticomunismo y la oposición a las formas que estaba asumiendo el apoyo a Cuba en las acciones de 
otros reformistas fueron los dos elementos que el reformismo 'democrático' tomó como bandera” (Pis Diez, 2018 , p. 232). El enfoque metodológico del presente artículo no permite describir trayectorias militantes, sin embargo la bibliografía sostiene que el reformismo liberal no obturó la influencia de los comunistas ni de otras tendencias de izquierda no reformistas.

Estos sectores rechazaron activamente la intervención en julio de 1966. Asimismo, renunciaron el rector Roberto Ciafardo, todos los decanos y los directores de colegios universitarios. La dictadura designó como rector-interventor a Santiago Gorostiague. Las protestas se prolongaron hasta octubre (Bonavena, 2012; Pis Diez, 2019). Con la excepción de la Facultad de Arquitectura, el impacto de las renuncias y cesantías fue menor al de la Universidad de Buenos Aires (UBA) (Suasnábar, 2004, p. 65), sin implicar un aval docente para las autoridades (Garatte, 2012, p. 61). En ese sentido, Suasnábar esgrimió que la voluntad menos abigarrada de su cuerpo docente en 1966, le permitió luego una mayor cohesión colectiva que procesó de un modo más homogéneo los conflictos sociales, por lo menos hasta 1972 cuando el fraccionamiento se hizo evidente (2004; p. 69, p. 76 y p. 106).

\section{ESTADO DE LA CUESTIÓN Y APROXIMACIÓN TEÓRICO-METODOLÓGICA}

Las posiciones sobre el caso platense se inscriben en las explicaciones sobre las movilizaciones universitarias en la Argentina de los años ‘ 60 y ‘70. En los primeros textos posteriores al período se estableció un paradigma dominante. Las perspectivas conceptuales combinaron hermenéutica, historia política, social, cultural y/ o intelectual (Gillespie, 1987, p. 96; James, 1999, p. 314 y ss.; De Riz, 2000, p. 95; Tortti, 2000, p. 148, Altamirano, 2001, p. 123, Barletta, 2001; Sarlo, 2001, p. 85; Sigal, 1991, p. 71) y el análisis cualitativo de discursos y testimonios orales, casi exclusivamente de un sector, ofreciendo una asociación estrecha de radicalización y peronización. Estas investigaciones se concentraron en la UBA, infiriendo que sus conclusiones eran extrapolables a otras casas.

En consonancia con tales miradas, Ana Julia Ramírez (1999) sostuvo de modo pionero que la radicalización platense se produjo en un marco de profunda crisis del reformismo y creciente influencia del peronismo entre los alumnos. Las investigaciones recientes ofrecen, por ejemplo, diferentes estimaciones sobre la influencia de la Federación Universitaria para la Revolución Nacional (FURN), la principal agrupación peronista en la UNLP. Colegas inspiradas por la noción de "nueva izquierda" le asignan gran injerencia (Simonetti, 2002, Lanteri, 2009 y Pis Diez, 2020), al igual que dos libros periodísticos (Amato y Boyanovsky Bazán, 2008; Alessandro, 2011), mientras otros cuestionaron su gravitación (Bonavena, 2012; Nava y Romá, 2011, Nava, 2013 y 2018). Pese a las disonancias, los textos del siglo XXI no proclaman la caducidad del reformismo o la irrelevancia de la izquierda no peronista.

Como se observa, el conocimiento sobre el movimiento estudiantil de la UNLP suma una cantidad considerable de escritos, focalizados en etapas o grupos, aunque no existe un trabajo científico global acerca del movimiento estudiantil platense en esta década. El artículo de Agustín Nava (2018) constituye el esfuerzo más sistemático de análisis de las acciones entre 1969 y 1972. Coincidimos con varios aspectos de su metodología y con sus conclusiones. No obstante, nuestra escala temporal más amplia nos permite marcar continuidades y rupturas con el período precedente, entre el golpe de Estado de 1966 y 1968, así como con la etapa posterior, durante el tercer peronismo. Este ejercicio ofrece mayor fuerza a ciertas tesis, como la vigencia del reformismo y la no asociación entre peronización y radicalización, así como abre luz sobre dinámicas de la contienda política contenida en 1967 o en 1973 y las respuestas frente a una lógica represiva focalizada, sucia y a-legal, como la que se vivió desde 1970, con una espiral en años anteriores al último golpe de Estado. Con esto brindamos una mirada global fundada en datos sobre el movimiento estudiantil de la UNLP entre 1966 y 1976.

Con una mixtura entre marxismo y sociología histórica reconstruimos los enfrentamientos sociales, considerados el “... operador teórico en el marco del análisis de las relaciones sociales, de su construcción 
y de su destrucción” (Marín, 2009, p. 46). Este punto de partida no desconoce aspectos discursivos y de sociabilidad, pero sostiene que la observación de las acciones contenciosas constituye una herramienta heurística fundamental para el estudio de un movimiento de lucha. Armarmos series estadísticas con cantidades y modalidades de acción, protagonismos y demandas, que permiten describir ciclos de movilización (Tarrow, 1997, p. 263). La radicalización estudiantil se entiende como la “... expansión de los marcos de la acción colectiva a listas de reivindicaciones más extremas y la adopción de formas más transgresivas de contienda" (McAdam, Tarrow y Tilly, 2005, p. 76). Desde esta perspectiva fue demostrado el predominio de las agrupaciones reformistas y de izquierda no peronistas en los enfrentamientos estudiantiles en Buenos Aires (Bonavena, Califa y Millán, 2018), Córdoba (Califa y Millán, 2020), Corrientes y Resistencia (Millán, 2017), La Plata (Nava, 2018), Rosario (Califa, 2020) y Tucumán (Califa y Millán, 2021).

Aquí analizamos las luchas estudiantiles en la UNLP en consonancia con este enfoque. Esta mirada no habilita una descripción de trayectorias militantes. No obstante, el trazo general permite a futuras indagaciones inscribir las descripciones cualitativas de experiencias en las magnitudes de las confrontaciones. En ese sentido, este artículo puede robustecer enfoques alternativos.

En términos metodológicos analizamos los enfrentamientos sociales protagonizados por estudiantes de la UNLP identificados en tanto tales. La fuente es una base de datos de luchas estudiantiles entre los golpes de Estado de 1966 y 1976 (Bonavena, 1990; de aquí en más BDB), disponible en el Instituto Gino Germani. Esta es una cronología diaria de acciones contenciosas protagonizadas por estudiantes en Argentina, construida con el registro de periódicos de circulación nacional y local. En La Plata incluye El Día (en toda la década) y El Argentino (entre 1972 y 1973). El primer matutino fue fundado en 1884, mientras que el segundo lo fue en 1906 y se editó hasta 1965, reapareciendo fugazmente en 1972 y 1973 ligado al Partido Justicialista (PJ) (Panella, 2018, p. 2). El Día era el medio gráfico dominante de la ciudad. Se trataba de un diario interesado en la vida universitaria (ver los titulares seleccionados por Katz, 2004, pp. 145-153). El director David Kraiselburd era crítico de Montoneros, a quiénes tildaba de "Tacuaras de izquierda" por su política en las facultades que consideraba autoritaria y de adoctrinamiento. Su secuestro y asesinato por esta organización en julio de 1974 tuvo repercusiones en los claustros, con pintadas alusivas (Katz, 2004, p. 228). A su vez, El Día colaboró con la última dictadura como agente de inteligencia encubierto y propagandista (Bernasconi, 2015, p. 10). Para el tratamiento de esta fuente seguimos los señalamientos de Franzosi (2017) para quién los sesgos de los diarios se localizan más en la presentación que en la aparición o no de los eventos, siendo improbable que un acontecimiento público relevante sea omitido. ${ }^{1}$ Aquí trabajamos con identificadores de enfrentamiento social y mediante la codificación extraemos la información de su contexto semiótico, separándola de los juicios de valor.

Desde 2006 realizamos sucesivas pruebas de fiabilidad y validez en distintos repositorios documentales (de hecho, en este escrito recurriremos también al diario La Opinión entre 1973 y 1975). Los recortes temporales aleatorios que contrastamos con resultados previos en pos de detectar posibles errores y/o omisiones corroboraron la labor pretérita, mientras el control con la bibliografía construida con enfoques distintos y semejantes al nuestro constató los eventos citados, incluso en textos no científicos, testimoniales o periodísticos

Dentro de cada hecho de enfrentamiento social puede registrarse una o varias acciones. Para nuestra década encontramos 2.336 acciones en el marco de 1.588 hechos. El código está formado por diez variables y más de cien categorías. A medida que presentemos los resultados detallaremos su contenido y las dificultades que nos llevaron a establecer seis variables con sistemas categoriales no excluyentes (tipo de acción, protagonista/ $\mathrm{s}$, reclamo/s, escenario, aliado/s y enemigo/s) y cuatro excluyentes (lugar, fecha, cantidad de participantes y facultad). En el análisis presentaremos sus valores y sus principales co-variaciones.

En términos operacionales, utilizamos una planilla con un encabezado que desglosa el código de cada variable y listamos uno por uno los enfrentamientos, a los que asignamos el/los valor/es de cada categoría. En un hecho pueden leerse distintos identificadores, por ejemplo "Al finalizar la asamblea una parte de los 
asistentes salió en marcha a la calle, al llegar a la esquina chocaron con la policía”. En ese registro constan tres acciones y tres formas: asamblea, marcha y choque con la policía. A su vez, certificamos que el trabajo de Nava (2018) arribó a conclusiones semejantes pero en una etapa más acotada. A continuación exponemos los valores de las variables.

\section{Ciclos, Formas de ACción y PROTAgonistas}

Un desglose del activismo platense entre 1966 y 1976 arroja la siguiente evolución:

GRÁFICO No 1

Construcción propia en base a la BDB

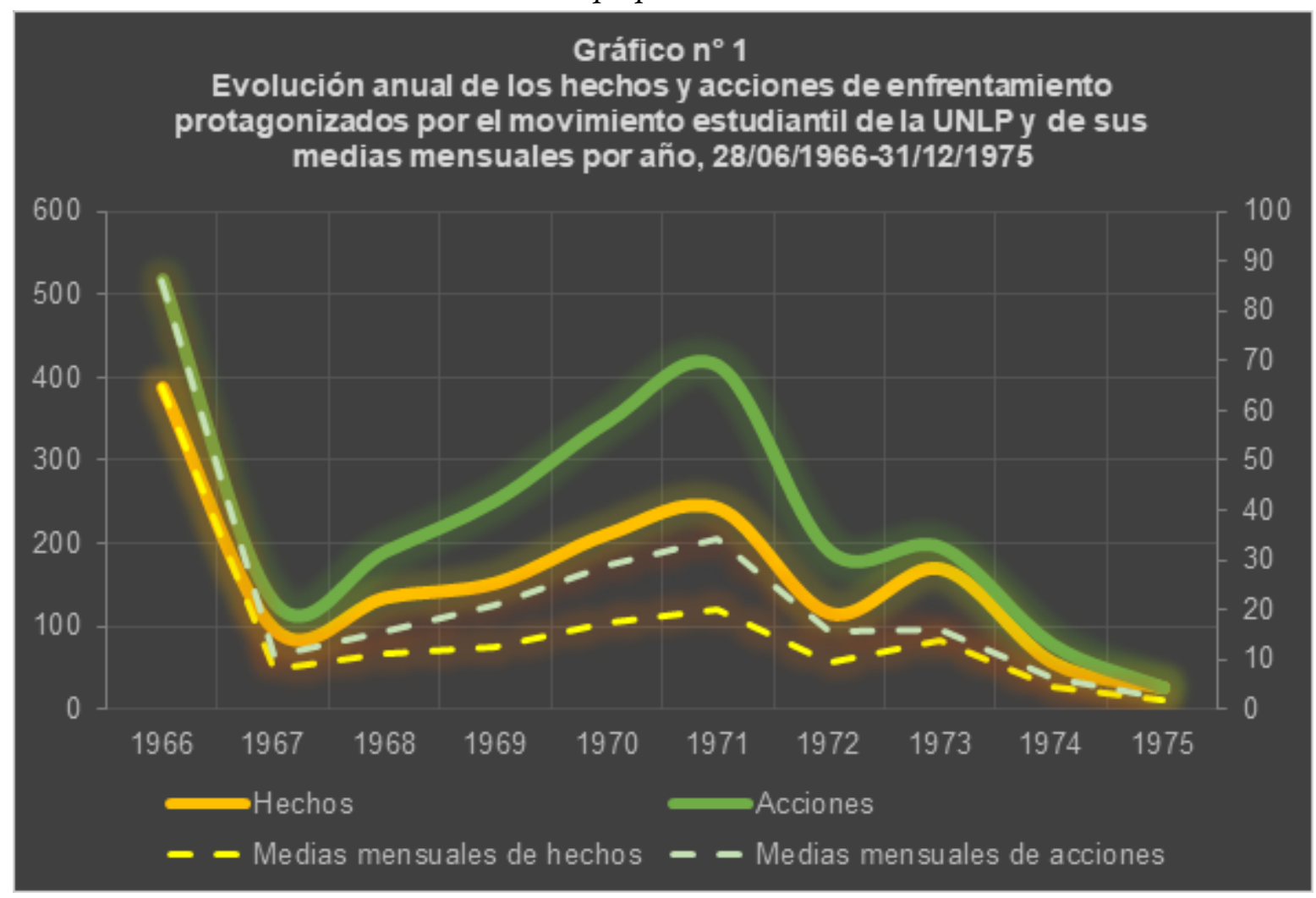

En una primera lectura observamos dos picos (1966 y 1971), un proceso de ascenso (1968-1971) y dos caídas: una abrupta (1967) y otra escalonada (1972-1975). Asimismo, la cuesta de las acciones resulta más empinada que la de los hechos, ensanchándose la brecha durante los años de fuerte activismo y reduciéndose en los de reflujo. Esto quiere decir que en ese sub-período resultó más usual que determinadas acciones, como una asamblea o un acto, derivaran luego, sin solución de continuidad, en una marcha y, tal vez, en choques con la policía. La mayor complejidad de los hechos y su tránsito de modos contenidos a disruptivos indican tanto la disposición al enfrentamiento del movimiento estudiantil como el recrudecimiento de la represión.

En la ciudad de las diagonales, como en otras urbes argentinas, la resistencia al golpe de Estado y, sobre todo, a la intervención universitaria de 1966, se caracterizó por una proliferación de prácticas contenciosas difícil de parangonar. Agosto y septiembre, con 105 y 186 hechos, concentraron tres cuartas partes de los enfrentamientos. Fueron meses de gran conflictividad, por la intervención y luego por el asesinato policial del estudiante Santiago Pampillón en Córdoba.

En consonancia con tendencias nacionales, 1967 fue un año de retroceso. No obstante, este caso concentra casi el 45\% de los registros correspondientes a Buenos Aires, Córdoba, La Plata, Rosario y Tucumán. Una 
de las principales causas fue la intensa campaña de rechazo en la UNLP a la nueva ley universitaria de la dictadura, que entre marzo y mayo acaparó cerca de 40 hechos; otra la peculiarmente elevada cantidad de acciones en memoria de Pampillón.

Durante 1968, año axial para los movimientos estudiantiles del mundo, en Argentina tuvo lugar una recomposición que, sin alcanzar las cotas de otras latitudes (Bonavena y Califa, 2018), comenzó un ascenso que se prolongó hasta 1971 e inspiró investigaciones que vislumbraron "el 69 platense". (Castillo y Raimundo, 2012). A la luz de los datos de una década, entendemos que se trata de una conclusión objetable. Observamos, por ejemplo, que el hiato de 1967 a 1968 resulta matemáticamente comparable a la distancia que separa 1970 de 1969, con incrementos anuales del 38\% y 37\% respectivamente. Pero, desde un punto de vista sociológico se trata de situaciones cualitativamente diferentes. En primer término, porque el segundo incremento no puede atribuirse a un "efecto rebote" tras una sensible baja, sino que representa un alza dentro de un período más amplio de crecimiento. En segundo, porque tras el Cordobazo puede afirmarse que la dictadura había perdido la iniciativa. En tercer lugar, nunca hubo una disparidad tan acusada entre la suba interanual de hechos y la de acciones como en 1969. Esto transformó la dinámica de la contienda: recurrentemente quienes participaban de actos o asambleas salían a las calles sin solución de continuidad.

El ascenso de la cantidad de acciones de la militancia estudiantil de la UNLP entre 1969 y 1971 se inscribe, también, en una tendencia de alcance nacional, pues coincide con las curvas que se han trazado para Córdoba, Rosario y Tucumán (Califa y Millán, 2019). La peculiaridad es que los colectivos de alumnos platenses comparten la trayectoria cuantitativa con los universitarios que protagonizaron alzamientos obrero-estudiantiles y populares conocidos como los “azos", sin que haya existido un "Laplatazo". El pico de 1971 tuvo dos disparadores: el reclamo por la libertad del estudiante de Ingeniería Carlos Mosquera y la solidaridad con los trabajadores de Petroquímica Sudamericana, que invitaron a los estudiantes a sus asambleas, concurrieron al comedor universitario y se unieron en las calles (Raimundo, 2012, p. 193 y ss.; Bretal, 2008, p. 80 y ss.).

El cambio de los datos se corresponde con una transformación del régimen político que abarca el período del Gran Acuerdo Nacional (GAN) desde mediados de 1971 y la primera mitad del tercer peronismo dos años más tarde. En consonancia, se propiciaron instancias de diálogo, cuando no de incorporación de grupos estudiantiles a las estructuras de los principales partidos políticos, con la expectativa de contener el proceso de movilización y aislar a las corrientes radicalizadas. Para los adherentes a las posturas revolucionarias, caía lo más duro de una represión selectiva, muchas veces clandestina y ejecutada por agentes para-estatales (Califa y Millán, 2016). Estas tendencias prosiguieron con la llegada del peronismo al Poder, donde notamos la continuidad del declive dela activación y, como se verá, de las acciones más transgresivas. Tal vez el relato de Alessandro sobre las Primeras Jornadas de Cultura Nacional en 1973 (2011, p. 155 y ss.), auspiciadas por las autoridades, permita una apreciación cualitativa de un proceso de institucionalización del movimiento estudiantil, con anclaje en lo que Tilly denominó "prácticas prescritas" en una democracia de baja capacidad (2006, p. 81).

La fase siguiente se caracterizó por el ejercicio del terrorismo de Estado en las universidades bajo la llamada "Misión Ivanissevich", desde septiembre de 1974. Paralelamente en La Plata, los secundarios protagonizaron un importante ciclo de luchas por el boleto estudiantil en 1975, que conllevó al secuestro y desaparición de varios de sus líderes bajo la dictadura (Seoane y Ruiz Núnez, 2011, p. 41 y ss.).

Hasta el momento hemos tomado todas las acciones como equivalentes, pero ello puede inducir a errores. Nuestra variable tipos de acción abarca 19 categorías, aquí reagrupadas en cinco: "Declaraciones y/o comunicados"; "Acción institucionalizada" (conferencia de prensa, acto, asamblea, huelga de hambre, huelga universitaria de escala nacional, local o por unidad académica); "Acción directa sin violencia” (marcha, movilización, concentración y toma sin control del edificio); “Acción directa con violencia” (acto relámpago, enfrentamiento con la policía, barricada, toma con control del edificio, detonación de explosivos y ataque armado) y "Otros". Entre las categorías "Acción institucionalizada" y "Acción directa sin violencia” existen 
hechos cuya clasificación resulta problemática. Dado que diferenciamos las acciones directas en función del ejercicio de la violencia, registramos dentro de las primeras las huelgas de hambre y estudiantiles.

En el conjunto de la década la acción estudiantil directa con violencia acumula 687 registros, un 29,7\% del total. Casi en la misma línea, la acción institucional reporta 675 casos y el 29,2\%. Muy cerca se encuentran las declaraciones, sumando 647 y alcanzando el $28 \%$. Notoriamente por debajo se ubica la acción directa sin ejercicio de la violencia, con 203 reiteraciones y poco menos del 9\%. Como se observa en otros trabajos, la violencia en el caso platense ocupó una porción menor de las acciones en comparación con los sucesos de Córdoba, Rosario o Tucumán, pero mayor que a la de la Buenos Aires (Califa y Millán, 2019; Califa, 2020; Califa y Millán, 2020 y Bonavena, Califa y Millán, 2018).

Cuando agrupamos la acción directa nos encontramos con el $38 \%$ de los casos, al tiempo que las declaraciones y las formas institucionalizadas reúnen el 57\%. Esto significa que entre los golpes de Estado de 1966 y 1976, poco menos que 4 de cada 10 acciones implicaron alguna forma disruptiva.Estos guarismos arrojan una imagen general, pero la evolución de este movimiento depara otras perspectivas. En el siguiente gráfico se observan sus proporciones anuales:

GRÁFICO No 2

Construcción propia en base a la BDB

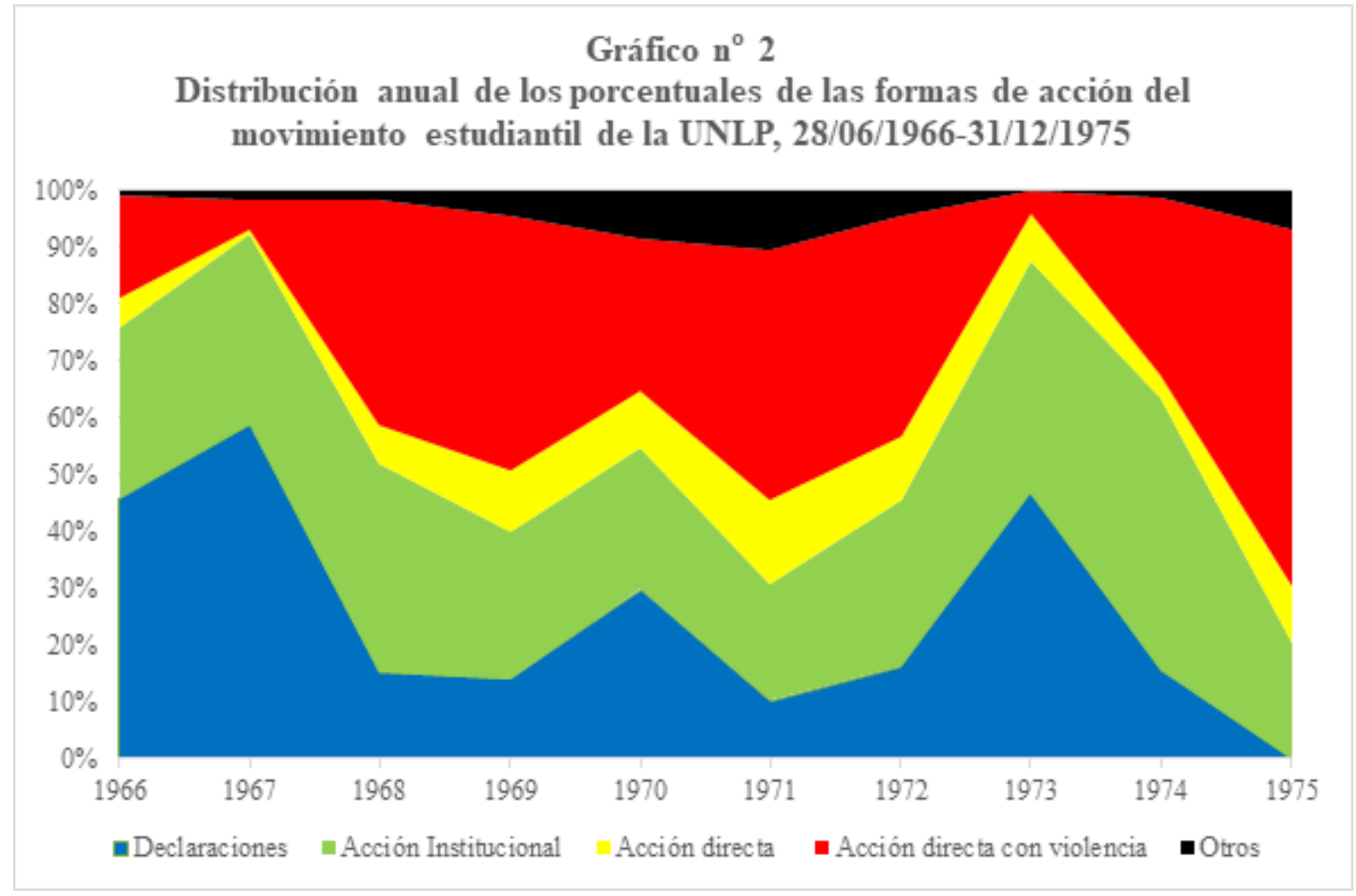

En el tramo inicial de la dictadura, entre 1966 y 1967, fue patente la importancia de las declaraciones y la acción institucional. Esto se replica durante la primera parte del peronismo, en los años 1973 y 1974, aunque en el último notamos una drástica caída de las declaraciones.

Podemos advertir que el período de ascenso de 1968 a 1971 se encuentra signado por el predominio de la acción directa con violencia, en consonancia con lo observado en otros casos mencionados. No obstante, a excepción de 1971, la acción institucional se mantiene cercana a su media. Aquí resaltamos que la creciente trajo un incremento de formas transgresivas de acción. Fuera de las etapas de ascenso la acción directa con violencia también predomina en 1972 y en 1975 y concentra una proporción considerable en 1974. Bajo el GAN prevalecen actos relámpago, enfrentamientos con la policía y barricadas, hechos protagonizados 
por centros, federaciones y agrupaciones estudiantiles reformistas, de izquierdas y/o peronistas combativas. En cambio, durante el último bienio del peronismo, en un contexto de merma militante, dentro de las modalidades violentas imperan los ataques armados. En este sentido, la relación del movimiento estudiantil platense con la violencia política presenta notorias similitudes con las de otras ciudades (Millán, 2020: 111). En este caso, era gravitante la Concentración Nacional Universitaria (CNU) (Carnagui, 2012), que tuvo sus respuestas de Montoneros, como el asesinato de Martín Salas (Cecchini y Elizalde Leal, 2013, p. 40).

Otra dimensión son los protagonismos estudiantiles. Para esta variable el código distinguió 27 categorías no excluyentes, pues una acción puede haber sido realizada por más de un grupo. Para la lectura trazamos seis conglomerados: "Centros y Federaciones", “Agrupaciones Reformistas” (los comunistas del Movimiento de Orientación Reformistas, MOR, los radicales de Franja Morada, FM, los socialista del Movimiento Nacional Reformista, MNR, la izquierda nacional nucleada en la Agrupación Universitaria Nacional, AUN, y otras reformistas), "Agrupaciones de Izquierda" (las maoístas del Frente de Agrupaciones Universitarias de Izquierda, FAUDI, y la Tendencia Universitaria Popular Antiimperialista Combatiente, TUPAC, la trotskista de la Tendencia Estudiantil Revolucionaria Socialista, TERS, el guevarista FEP-PRT, la Línea de Acción Popular o los Grupos Revolucionarios Socialistas), “Agrupaciones Peronistas" (FEN, Juventud Universitaria Peronista, JUP, Integralismo y demás), "Grupos de Derecha” y "Otros/No informados".

\section{GRÁFICO No 3}

Construcción propia en base a la BDB

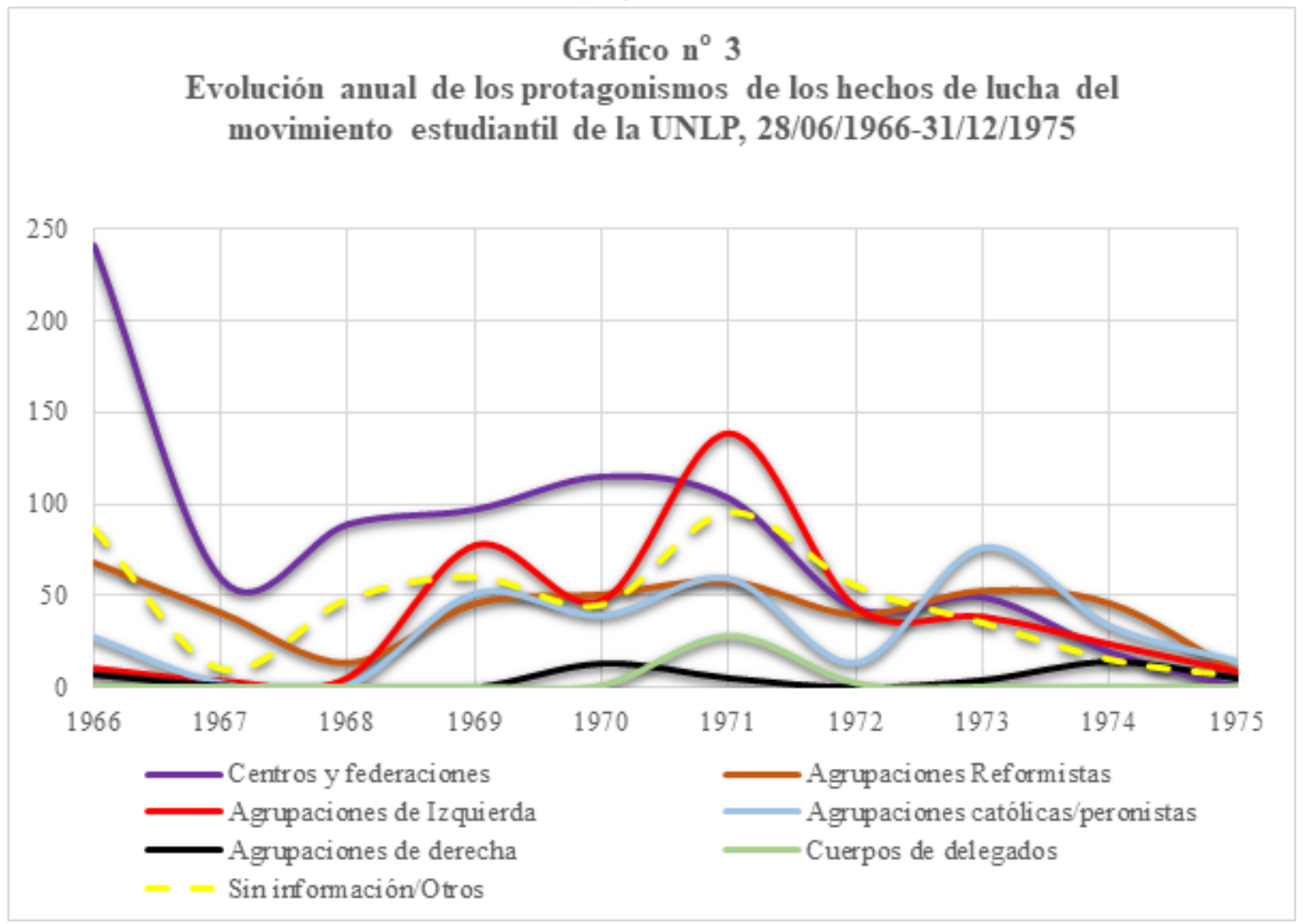

En este nuevo gráfico notamos que hasta 1973 los centros y federaciones se encuentran a la vanguardia, con la excepción del agitado 1971. Una muestra del clima efervescente reside en la importancia que cobraron durante ese último año los estudiantes no identificados. Dentro de los organizados, la agrupación más fuerte surgió del reformismo. Franja Morada, al frente de varios centros y la FULP, protagonizó más de 200 hechos durante la década y desde 1973 colocó a Federico Storani, de la Facultad de Derecho, en la presidencia 
de la FUA "Córdoba". Esta fuerza se encontraba integrada en un proceso de giro a la izquierda de las juventudes radicales bonaerenses, con varias expresiones peculiares en la ciudad de las diagonales, como el grupo encabezado por el abogado Sergio Karakachoff. A la zaga dentro del reformismo, con algo más de la mitad de los protagonismos, se ubicaba el MOR comunista, presidencia de la FUA "La Plata".

La izquierda marxista experimentó un crecimiento en el período de ascenso. La agrupación más poderosa era el FAUDI, surgida en 1967 de una ruptura del Partido Comunista y luego enrolado en el Partido Comunista Revolucionario, que protagonizó más de un tercio de las acciones. En 1970 las corrientes anarquistas y socialistas desprendidas de Franja Morada emparejaron la disputa con FAUDI (Nava, 2013, p. 109 y ss.). Asimismo, con el final del ascenso de masas remitió buena parte del predicamento de estas y otras organizaciones de izquierda, mientras ganaban terreno los reformistas.

Estas tendencias reconocieron un vuelco tras el triunfo electoral del Frente Justicialista de Liberación en 1973, cuando soplaron vientos en favor del peronismo universitario. En lo que constituyó un verdadero espaldarazo a estas fracciones estudiantiles, el 31 de mayo fue designado rector de la UNLP el filósofo Rodolfo Agoglia. Según nuestros datos, aquel fue el único año de la serie en el cual las tendencias peronistas estuvieron a la cabeza en cantidad de acciones, algo similar a lo ocurrido en la UBA (Bonavena, Califa y Millán, 2018). Dentro de este arco, la FURN acaparó la mitad de los protagonismos. Esta corriente se reagrupó con su escisión del Frente de Agrupaciones Eva Perón (FAEP) en la JUP-Montoneros de la UNLP. La literatura sobre el estudiantado platense ha destacado su importancia en el diseño de las "Bases para la Nueva Universidad" (Lanteri y Meschiany, 2015; Barletta, 2018; Pis Diez, 2020), su aporte barrial (Robles, 2011, p. 6), e incluso testimonió sobre su influjo en el PJ local (Chaves, 1998, p. 43).

A diferencia de la UBA, la JUP no participó de los comicios estudiantiles de 1973. En 1974, cuando se presentó, su performance resultó destacable y paradójica. Fue primera en el score, pero conquistó sólo tres centros donde la cantidad de sufragios era un porcentaje exiguo: Humanidades, Odontología y el Museo de Ciencias Naturales. ${ }^{2}$ Los peronistas alcanzaron luego la presidencia de la FULP en una alianza muy pareja con el MOR y por detrás con la poderosa lista independiente de Ingeniería, mientras la derrotada Franja Morada advertía que no compartía la política de la JUP y no comprendía por qué los comunistas, de posiciones universitarias similares, avalaban a la agrupación justicialista y no a la radical. ${ }^{3}$ Para 1975 , frente a una feroz represión, su caída fue paralela a la del resto.

En estas distribuciones no encontramos correlación entre el incremento de la incidencia del peronismo en el movimiento estudiantil platense y la radicalización, lo que nos permite suponer que tampoco existe un nexo causal. El crecimiento del registro de estudiantes sin identificación en los años más agitados convive con el incremento de las izquierdas. No hay datos suficientes, pero es posible conjeturar que parte del crecimiento de la FURN y la FAEP desde 1973 se debió a la incorporación de algunos de estos activistas. Importa, en todo caso, que su enrolamiento en estas agrupaciones se corresponde con un cambio en las formas de acción signado por el declive de la disposición al enfrentamiento. Nuevamente pensamos que un escrito muy diferente al nuestro puede ilustrar las cifras cuando señala que bajo el gobierno de Cámpora “... los peronistas, eran 'orgánicamente' [...] compelidos a cesar en sus manifestaciones, por sus conducciones [...] con el argumento que de esa forma se le hacía el juego a la derecha y a la izquierda no peronista...". (Alessandro: 2011, p. 144). Esto fue verdaderamente conflictivo, como lo ilustran las tomas del Instituto Superior de Investigaciones de Físico-Química, (BDB, junio1, pp. 59 y 65), las de Humanidades (BDB, junio2, p. 22) o las del Colegio Nacional, donde la docencia se oponía (BDB, junio2, pp. 23, 28, 36 y 39).

No obstante, las precisiones sobre estas variables resultan insuficientes para caracterizar las luchas estudiantiles en la UNLP. En lo que sigue consideraremos los reclamos, las alianzas y los escenarios de la acción. 


\section{Reclamos, aliados y escenarios}

Las lecturas sobre la militancia universitaria de las décadas de 1960 y 1970 a nivel global resaltan la centralidad de lo político. En Argentina muchos se hicieron eco de las palabras de Beatriz Sarlo, quien sostuvo que el peronismo revolucionario, muestra suficiente de la militancia, había incurrido en una "pérdida de especificidad de la cuestión universitaria" que lo llevó a su derrota (2001, p. 103).

Existen dos formas de contrastar tal hipótesis. Primero, mediante investigación de las ideas universitarias de la izquierda del peronismo. Sergio Friedemann (2015) demostró la existencia de un cuerpo relativamente desarrollado de concepciones sobre los medios y fines de la actividad de las facultades por parte de este sector de la militancia en la UBA.

La segunda, que elegimos nosotros, se enfoca en un análisis de las demandas del movimiento estudiantil a lo largo de una década, pues la caída del peronismo marcó el final de una larga y compleja experiencia que lo excedía. Tomamos como referencia la distinción del sociólogo uruguayo Aldo Solari entre "la dimensión gremial, la de política universitaria y la de política general” (1968, p. 53) y, como él señala, reconocemos la dificultad para distinguirlas. El marxismo clásico ha estudiado esta relación en la clase obrera dando cuenta de su interdependencia. Respecto del movimiento estudiantil, constatamos ejemplos de reclamos corporativos que interpelan al Estado, como sucedió con la pugna contra el examen de ingreso. Al mismo tiempo, como señaló Fred Hallyday, las motivaciones pueden cobrar giros: “... en muchos países hubo una acumulación inicial de militancia por cuestiones académicas que después pasó a la lucha por cuestiones políticas..." mientras que “... también hay ejemplos en los que una campaña inicialmente política (...) repercute en los recintos universitarios y denota una rebelión interna de la educación superior.” (1971, p. 396). No obstante las superposiciones y continuidades, en ocasiones unas demandas predominan sobre otras (Poulantzas, 1971, p. 97). En nuestro contexto, la política se concebía cómo una actividad revolucionaria por parte de la militancia de izquierda. En ese sentido, más allá de la difusión de prácticas, existían diferentes niveles de intervención.

Con el propósito de observar sistemáticamente esta faceta, codificamos la variable reclamos en 13 categorías no excluyentes. En cada hecho consignamos todos los reclamos esgrimidos, porque lo que nos interesa es la evolución del conjunto de demandas y las motivaciones de cada enfrentamiento. A continuación exponemos los resultados en seis conjuntos: "Reclamos académico/universitarios" (autonomía y cogobierno, cuestiones académicas, bienestar estudiantil e ingreso irrestricto); "Política Universitaria" (cuestionamiento contra funcionarios y/o profesores y crítica de la política universitaria gubernamental); "Cuestiones políticas" (contra medidas y acciones políticas en el escenario nacional y/o internacional, solidaridad con otras luchas y memoria/homenaje a mártires), “Anti-represivo”, “Apoyo al gobierno y/o funcionario” (apoyo a funcionario, apoyo a la política educativa del gobierno o al gobierno en general) y "Otros".

Encontramos 2.312 registros de reclamos mencionados por alumnos y sus organizaciones de la UNLP. A lo largo de la década priman las "Cuestiones políticas" con el 30\%, seguidas por el rubro "Anti-represivo"con el 26\%. Más atrás se ubican los "Reclamos académico/universitarios", con el 17\%, y la "Política universitaria", 16\%. En el final aparecen "Otros” y "Apoyo al gobierno y/o funcionario", con el 6\% y el 5\%, respectivamente. Una primera ojeada constata la relevancia de las demandas políticas.No obstante, si sumamos reclamos universitarios y política universitaria obtenemos un tercio de las peticiones. Es decir, corren parejas a las cuestiones políticas, algo advertido por otros autores (Nava, 2018).

Por otra parte, la magnitud de las demandas contra la represión nos recuerdan la proporción de la acción directa con violencia. Estas cifras contribuyen a dimensionar el lugar de tales prácticas como un aspecto consustancial del intercambio político durante aquellos años, cuestionando la idea de una opción por la violencia. Las series anuales habilitan otra perspectiva: 
GRÁFICO No 4

Construcción propia en base a la BDB

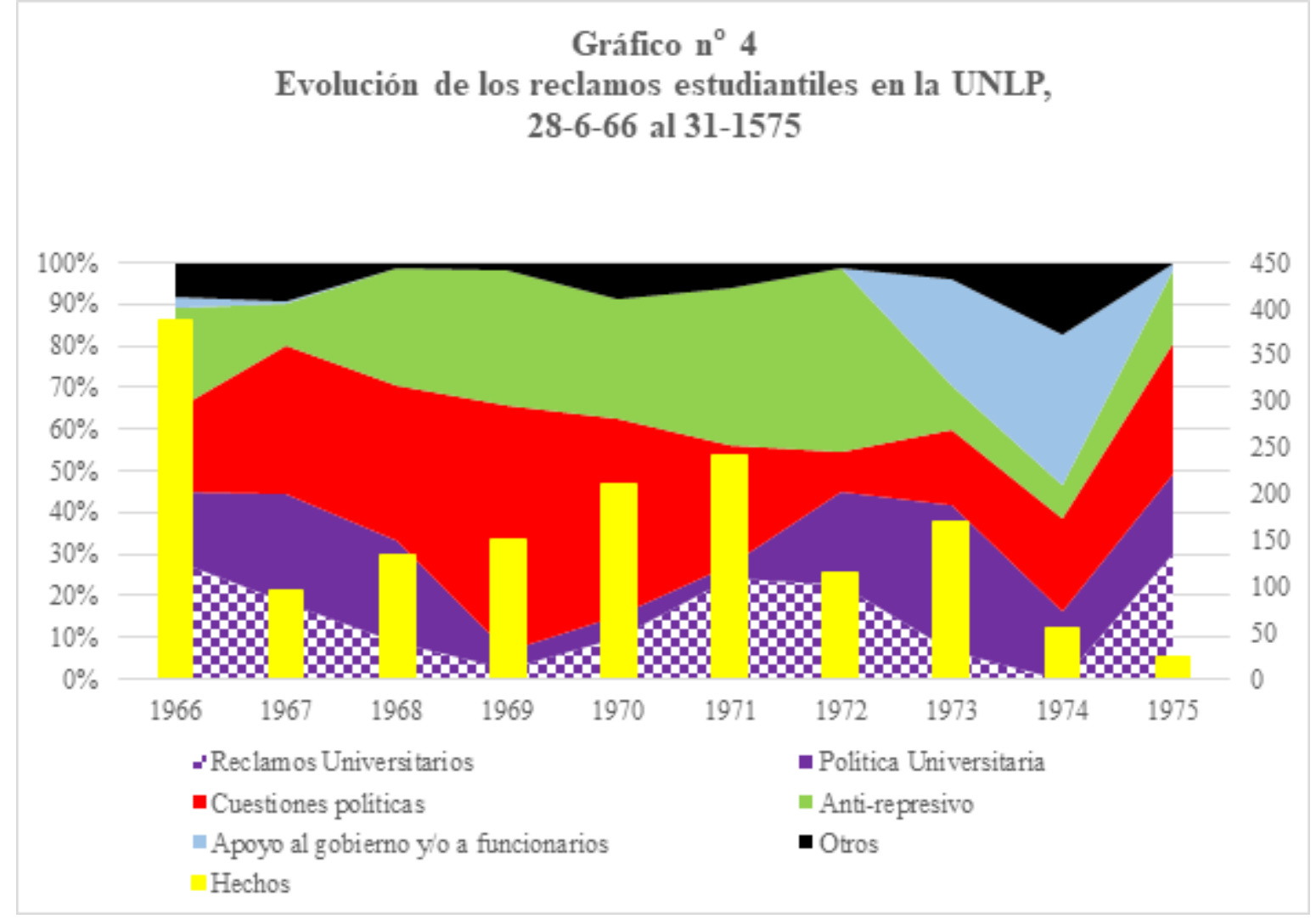

El comienzo de nuestro período se caracteriza por un auge de los reclamos universitarios y la política universitaria, demandas ligadas al rechazo de la intervención. La novedad de 1967 consiste en que, pese al contexto de desmovilización, las cuestiones políticas adquieren un peso preponderante, debido a la gravitación de la resistencia contra la nueva ley universitaria y de las acciones en recuerdo de Pampillón. La política ensanchó su proporción entre los reclamos en 1968 y 1969, sobre todo el segundo, cuando el Correntinazo, el Rosariazo y el Cordobazo de mayo azuzaron la radicalización. Durante 1970 los reclamos políticos perdieron fuerza (su mínimo fue en 1972), para estirarse luego paulatinamente.

Nuestras conclusiones se basan en una lectura cuantitativa, sobre la cual deberá profundizarse. Observamos que estas demandas se retrajeron en el principio del ascenso, pero recuperaron injerencia cuando la pendiente de hechos se hizo más escarpada en 1971. Las dos razones se atribuyen a un auge de los reclamos en las propias facultades, muchas veces por problemas de correlatividades de materias, reprobaciones masivas o intentos de cambios en los planes de estudios, y a la lucha por el ingreso irrestricto. La importancia de las demandas corporativas prosiguió su crecimiento durante el retroceso de 1972 y bajo el peculiar incremento de hechos de 1973, pero advertimos un cambio en su composición. Los repudios contra profesores y/ o funcionarios y, ya bajo el tercer peronismo, la discusión más general de la "política universitaria", que recuperó el vigor de 1967, ocuparon el lugar de las cuestiones académicas más puntuales. El último bienio de nuestro período, caracterizado por un sostenido retroceso en la disposición estudiantil al enfrentamiento, presenta un descenso de la importancia de los asuntos universitarios en 1974 y un crecimiento exponencial en 1975, con un reparto parejo de todas las categorías: desde la demanda por la autonomía y el cogobierno, pasando por el problema de las restricciones al ingreso hasta alcanzar un repudio a la política educativa de la "Misión Ivanissevich". El clima de violencia quedó expuesto el 8 de octubre de 1974 con el asesinato perpetrado por la CNU y la Triple A (Alianza Anticomunista Argentina) de Rodolfo Achem y Carlos 
Miguel, funcionarios de la UNLP y reconocidos militantes de la tendencia revolucionaria del peronismo, y la clausura de la universidad tras la asunción en el rectorado de Pedro José Arrighi, apoyado por la derecha peronista (Simonetti, 2002, p. 57; Carnagui y Abattista, 2014, p. 19; Lanteri y Meschiany, 2015, p. 8; Barletta, 2018, p. 15).

La evolución de la importancia de los reclamos anti-represivos presenta una fuerte asociación con el nivel general de activación. En 1966 se ubicó cerca de la media, con un 25\%, se redujo sensiblemente en 1967 y creció entre 1968 y 1972, cuando alcanzó una presencia en el 44\% de los hechos. La creciente gravitación de las demandas anti-represivas se corresponde con el repudio a las acciones policiales frente a las movilizaciones, la aplicación de medidas de excepción, como la detención a disposición del Poder Ejecutivo Nacional durante el GAN del universitario Mosquera, o las prácticas parapoliciales, registradas ya en 1970 con el ataque armado de la CNU a la Facultad de Derecho (Alessandro, 2011, p. 109). A nivel local, este recorrido se corresponde con el de la acción directa con violencia. En paralelo con un declive de las prácticas represivas en 1973 y la primera parte de 1974, tales reclamos menguaron, para ascender en 1975.

El otro eje de consideración es el del apoyo a las autoridades universitarias, a funcionarios y/o al gobierno. A lo largo de la década resultó marginal, pero crucial durante los primeros años del trienio peronista, con un $25 \%$ y un $36 \%$. Urge aquí señalar la sintonía con el protagonismo de corrientes justicialistas en la acción estudiantil, así como la solidaridad de Franja Morada y el MOR.

Asimismo, durante el tercer peronismo creció la categoría "otros". En esta tendencia cobran relevancia las agrupaciones como la CNU, cuyas proclamas repudiaban a la militancia reformista, marxista y de la izquierda del peronismo. Carnagui y Abattista documentaron los ataques de finales de 1973 (2014, p. 12), aunquela detonación de explosivos se remontaban a las bombas contra el Centro de Estudiantes de Ingeniería, en mayo de 1970 (Alessandri, 2011, p. 105).

La comprensión de la politización nos conduce a observar los vínculos cooperativos del estudiantado con docentes, no docentes de la Asociación de Trabajadores de la Universidad Nacional de La Plata (ATULP), asalariados, religiosos, profesionales, partidos políticos y otros (comerciantes, familiares, etc.).

Una mirada panorámica de la década 1966-1976 arroja cifras que permiten analizar con más profundidad esta experiencia. En primer término, registramos 460 casos de algún tipo de participación de otros sujetos, lo que representa casi el 29\% de los hechos. En segundo lugar, los principales aliados son, por lejos, las fracciones asalariadas: las externas a la universidad concentran el 33\%, mientras que las internas suman el 39\%, docentes con $21 \%$ y no-docentes con $18 \%$. Finalmente, los partidos políticos y los profesionales registran $11 \%$ y $8 \%$, respectivamente. Una observación de las alianzas año tras año ilumina la cuestión 


\section{GRÁFICO No 5 \\ Construcción propia en base a la BDB}

\section{Gráfico $n^{\circ} 5$}

\section{Evolución de las alianzas del movimiento estudiantil de la UNLP,} 28-6-66 al 31-12-75

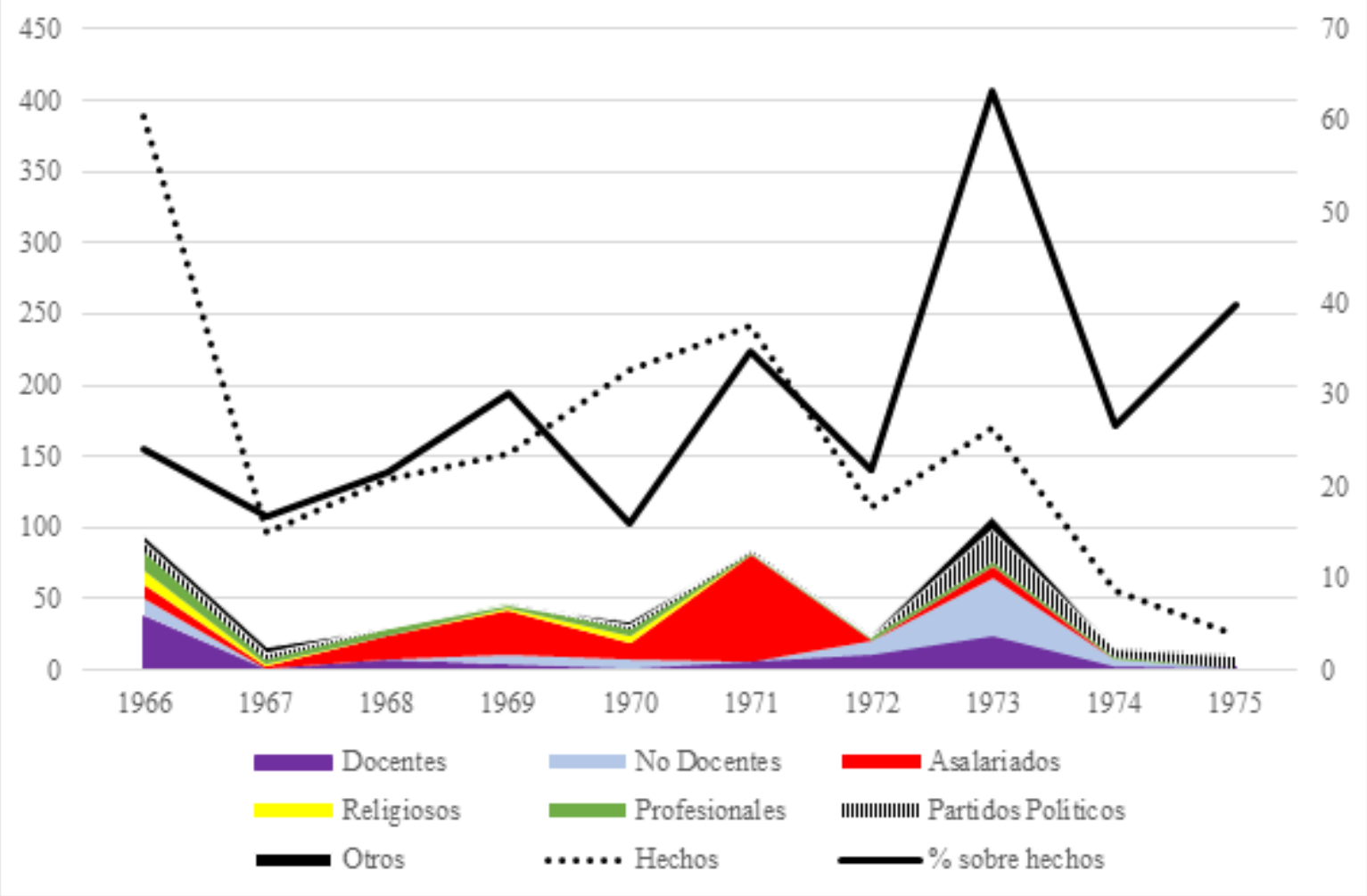

En primer lugar, no encontramos una correlación lineal entre la cantidad de hechos de lucha y la proporción de la participación de aliados del movimiento estudiantil. Vale resaltar, por ejemplo, el pico de 1966, donde la cooperación con otros actores resultó menor, o la caída de 1975, cuando cerca del $40 \%$ de los enfrentamientos unieron fuerzas. Asimismo, en el ciclo de ascenso entre 1968 y 1971 se hunden las alianzas durante 1970; mientras en la recuperación parcial de 1973 exhiben un saldo exorbitante.

En segundo término, y matizando las observaciones precedentes, el vínculo con la clase trabajadora es mucho más pronunciado durante los años de mayor confrontación. Un ejemplo es lo sucedido en Petroquímica Sudamericana.

En tercer lugar, notamos una fuerte gravitación de los docentes y no docentes (Godoy, 1995) entre los aliados durante la resistencia contra el golpe y la intervención universitaria en 1966, y en 1973, cuando el debate sobre política universitaria se agudizó. La importancia del activismo no-docente distingue al caso platense (Nava, 2020) y se enmarca en la especial incidencia de los/as trabajadore/as estatales en la conflictividad de la ciudad, donde acaparan más de la mitad de los conflictos en los años de mayor agitación (Nava, 2017, pp. 102/3).

En cuarto término, nos interesa marcar la evolución de una categoría marginal al principio, pero muy importante finalmente: los partidos políticos. Del salto de 20\% en 1973 pasaron a ser aliados hegemónicos durante los años siguientes. Esta tendencia se inscribe en dos procesos. Por un lado, la revalidación de los partidos como agentes en la contienda política, en un primer momento por la apertura democrática, en un segundo como refugio frente al ejercicio del terrorismo de Estado. Por el otro, la creciente influencia de las agrupaciones peronistas y la inscripción de Franja Morada ya definitivamente en la UCR. Estas magnitudes 
son comparables a las de la UBA y la UNR, más no a lo ocurrido en la UNC o la UNT (Bonavena, Califa y Millán, 2018; Califa, 2020; Califa y Millán, 2019 y 2020).

La dinámica de la lucha estudiantil y su interactividad con el proceso político puede apreciarse también en los escenarios de la acción. Para ello codificamos ocho categorías, acotadas a tres según su recurrencia: facultades, calles y otros (locales de partidos políticos, sindicales, religiosos, profesionales, locales y/o domicilios privados, entre otros).

En el conjunto de la década los edificios de la UNLP fueron el escenario del $71 \%$ de los hechos, una magnitud similar a la de la UBA pero distante de la de la UNC o la UNR, según los trabajos citados. El grueso de las facultades contribuyó con alrededor de un decil, nueva prueba de lo extendido del fenómeno militante local. Respecto a la calles, estas ofrecieron el locus para el $24 \%$ de los hechos, quedando en un $5 \%$ la amplia categoría "otros". Debe señalarse que en la construcción de estos datos las declaraciones, las acciones de menor costo subjetivo y organizativo, se atribuyen a las facultades.

GRÁFICO No 6

Construcción propia en base a la BDB

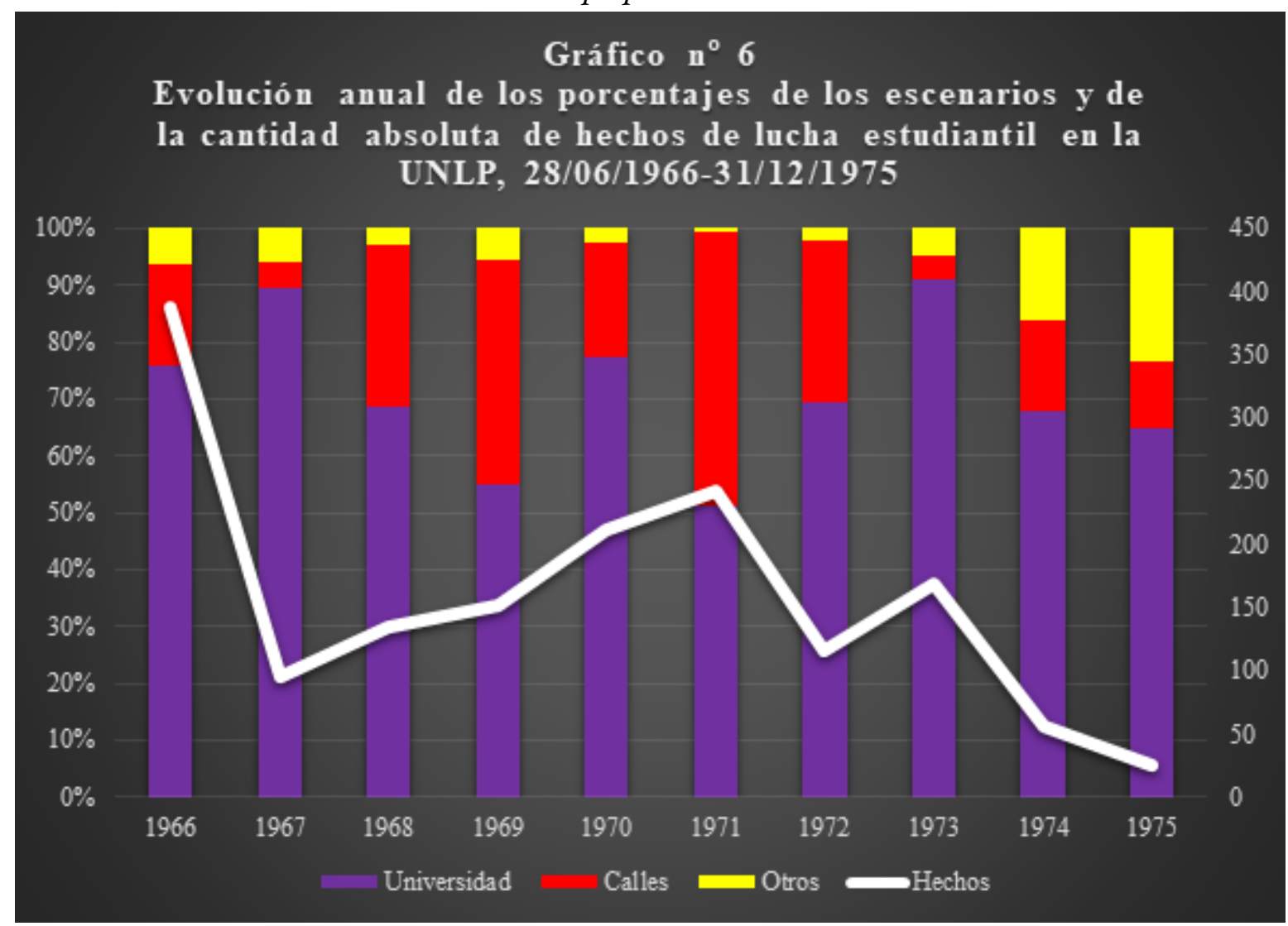

Como se observa, la preeminencia de las unidades académicas en tanto escenarios de confrontación resulta sustantiva en el comienzo del período analizado, 1966 y 1967, y desde 1973. Esta trayectoria sintoniza con los aliados del mundo universitario, así como con los reclamos propios a las facultades.

El salto a las calles se nota en 1968, crece en el 1969, declina en 1970, llega a su pico durante 1971 yel año siguiente sostiene destacadas proporciones. La impronta callejera se produce a la par del crecimiento de las cuestiones políticas y de los guarismos de acciones junto a los trabajadores.

Mientras que primero gravitaron los locales sindicales y, en menor medida, religiosos, sobre el final lo hicieron los partidarios: los peronistas en 1973, los radicales y comunistas cuando arreció el terrorismo de Estado. Bajo esta atmósfera, que se profundizó con la dictadura de 1976, fueron asesinadas 750 personas 
vinculadas a la UNLP (Piccone, 2010). En los años previos el influjo del peronismo en el movimiento estudiantil no acentuó el ejercicio de la violencia, no conllevó mayor coalescencia obrero-estudiantil, no incrementó su presencia en las calles y tampoco envalentonó los reclamos políticos. Para el caso platense no existe evidencia suficiente para asociar peronización y radicalización estudiantil.

\section{Conclusiones}

En este artículo ofrecimos un panorama general de las luchas del movimiento estudiantil de la UNLP entre los golpes de Estado de 1966 y 1976 a través del análisis cuantitativo de sus enfrentamientos sociales. Esta perspectiva ya fue aplicada a otros casos y, parcialmente, al de La Plata. No es la única posible o deseable, aunque por el momento es la que reúne el conjunto más numeroso de datos válidos y fiables. Por otra parte, la estrategia metodológica asumida no permite observar trayectorias particulares, ni describir procesos de lucha puntuales. Las conclusiones aquí presentadas suponen estas salvedades y esperamos que los trabajos cualitativos tomen este aporte para ubicar sus ricas descripciones.

En primer término, se observa que la dinámica local es consonante con la de otros movimientos estudiantiles de la Argentina. Así, tras el golpe y la resistencia inicial a la intervención universitaria de 1966, este movimiento comenzó a resurgir dos años después para alcanzar su etapa más beligerante en medio de los “azos", entre 1969 y 1971. Los temas políticos motivaron debates constantes, pero ello no impidió que las demandas corporativas, con un papel destacado de las protestas que conquistaron el acceso a la universidad, ocuparan un lugar central. En 1973, con la vuelta de las urnas, este movimiento se institucionalizó. Las organizaciones peronistas cobraron una relevancia inédita. El reformismo y, en menor medida, la izquierda marxista conservaron su gravitación, aunque el conjunto del movimiento perdió su perfil radicalizado, expresado en la lucha de calles. Lo que vino después, de la mano de una represión cada vez más aguda, fue una caída abrupta del activismo que a la postre puso fin a una década de protestas. Nos interesa señalar que las capacidades de respuesta del estudiantado frente a las acciones para-militares fueron diferentes: vigorosa en 1970 y 1971, débil en 1974 y 1975. En este sentido, la ampliación de la escala temporal, si lo comparamos con escritos de metodología similar, permite una ganancia explicativa: la lucha antirrepresiva, como cualquier proceso de confrontación, adquiere sus formas según los contextos.

Por otra parte, se observaron las peculiaridades platenses. Por un lado, la caída del activismo opositor en 1967, tras la consolidación de la intervención, no fue tan pronunciada como en otras partes. Asimismo, la recuperación posterior, si bien lejos de un "azo", fue más que importante de cara al movimiento obrero local. En ese punto resultó muy destacable la comunión con los trabajadores de la universidad, en especial los no docentes. Del mismo modo, el movimiento se plasmó a lo largo de todas las facultades con ratios similares de intervención y con el comedor universitario como emblema.

Este panorama invita a dos tareas: repensar ciertas hipótesis de uso común, como la asociación entre peronización y radicalización o la pérdida de la especificidad universitaria; y detallar las derivas del reformismo universitario y la izquierda marxista, menos apetecidos por los estudios cualitativos.

\section{Archivo}

Bonavena, Pablo. Las luchas estudiantiles en Argentina 1966/1976. Informe de Beca de Perfeccionamiento, Secretaría de Ciencia y Técnica, Universidad de Buenos Aires, 1990/2. Diarios de La Plata: El Día (1966-1975) y El Argentino (1972-1973).

$$
\text { La Opinión (1973-1975). }
$$




\section{REFERENCIAS}

Alessandro, J. (2011). La colina táctica del enemigo. Un recorrido por el pensamiento y la militancia de los universitarios platenses (1950/1975). La Plata: De La Campana.

Altamirano, C. (2001). Bajo el signo de las masas: 1943-1973. Buenos Aires: Ariel.

Amato, F. y Boyanovsky Bazán, C. (2008). Setentistas. De La Plata a la Casa Rosada. Buenos Aires: Sudamericana.

Barletta, A. (2018). Apuntes sobre un legado invisibilizado: Universidad y peronismo en la UNLP, 1972-1974. Colección Nuevas Bases Para La Reforma Universitaria 4. Buenos Aires: IEC-CONADU.

Barletta, A. (2001). Peronización de los universitarios (1966-1973). Elementos para rastrear la constitución de una política universitaria peronista. Pensamiento Universitario 9, 82-89.

Bernasconi, M. (2015). El vínculo entre prensa y dictadura. Un estudio sobre los discursos del diario El Día entre marzo de 1976 y marzo de 1978, (tesina de grado inédita). La Plata: UNLP.

Biagini, H. (2001). La Universidad de La Plata y el movimiento estudiantil: desde sus orígenes hasta 1930. La Plata: UNLP.

Bonavena, P., Califa, J. S. y Millán, M. (2018). ¿Ha muerto la Reforma? La acción del movimiento estudiantil porteño durante la larga década de 1966 a 1976. Archivos de Historia del Movimiento Obrero y la Izquierda, 12, 73-95.

Bonavena, P. y Califa, J. (2018). El '68 argentino. Luchas estudiantiles en los albores de un ascenso de masas. En P. Bonavena, y M. Millán (eds.). Los '68 latinoamericanos: movimientos estudiantiles, política y cultura en México, Brasil, Uruguay, Chile, Argentina y Colombia (pp. 201-232). Buenos Aires: IIGG-CLACSO.

Bonavena, P. (2012). Conflicto social y protesta en la ciudad de La Plata: el caso del movimiento estudiantil frente a la irrupción de la 'Revolución Argentina'. En C. Castillo y M. Raimundo (comps.), El 69 platense. Luchas obreras, conflictos estudiantiles y militancia de izquierda en La Plata, Berisso y Ensenada durante la Revolución Argentina (pp. 15-63). Buenos Aires: Estudios Sociológica Editora.

Bonavena, P. (2006). El movimiento estudiantil de la ciudad de La Plata (1966-1973). Cuestiones de Sociología, 3, 169-192. Recuperado de: https://www.cuestionessociologia.fahce.unlp.edu.ar/article/view/CSn03a07

Bozza, A. (2010). Espías, disturbios y barricadas. La radicalización estudiantil y los servicios de información. La Plata, 1968. El centenario de los estudios históricos en La Plata. Ciclo de Conferencias. Recuperado de: http://www.me moria.fahce.unlp.edu.ar/trab_eventos/ev.723/ev.723.pdf.

Bretal, E. (2008). Experiencias de organización y Lucha Sindical en el Gran La Plata: el caso de Petroquimica Sudamericana 1969-1973, (tesina de grado inédita). La Plata: UNLP.

Califa, J. S. y Millán, M. (2021). Las luchas estudiantiles en Tucumán entre los golpes de Estado, 1966-1976. Quinto Sol. Revista de Historia, 25, 1-24. Recuperado de: https://doi.org/10.19137/qs.v25i1.4844.

Califa, J. S. y Millán, M. (2020). De la resistencia universitaria a la rebelión popular y del pacto democrático al terrorismo de Estado. Un análisis cuantitativo del movimiento estudiantil de la Universidad Nacional de Córdoba (Argentina), 1966-1976. Historia y sociedad, 38, 176-204. Recuperado de: https://doi.org/10.15446 /hys.n38.80543.

Califa, J. S. (2020). Luchas, tendencias y corolarios del movimiento estudiantil de la Universidad Nacional de Rosario, 1966-1975. Avances del CESOR, 17, 1-22. Recuperado de: https://doi.org/10.35305/ac.v17i23.1290.

Califa, J. S. y Millán, M. (2019). La lucha estudiantil durante los azos. Córdoba, Rosario y Tucumán en perspectiva comparada, 1969-1972. Revista Conflicto Social, 12, 175-210. Recuperado de: https://publicaciones.sociales.ub a.ar/index.php/CS/article/view/5169.

Califa J. S. y Millán, M. (2016). La represión a las universidades y al movimiento estudiantil argentino entre los golpes de Estado de 1966 y 1976. HIb: Revista de Historia Iberoamericana, 9, 10-38. Recuperado de: https://core.ac.u k/download/pdf/159290388.pdf.

Carnagui, J. (2013) "El nacionalismo juvenil platense y la formación de la CNU”. Nuevo Mundo Mundos Nuevos. Recuperado de: https://doi.org/10.4000/nuevomundo.66038. 
Carnagui, J. y Abattista, L. (2014) La "depuración oficial” en las políticas educativas: la gestión Ivanissevich en el Ministerio de Educación de la Nación y su impacto en la UNLP. VIII Jornadas de Sociología de la UNLP, Argentina. Recuperado de: http://www.peronlibros.com.ar/content/carnagui-juan-y-abattista-maria-l-la-depu racion-oficial-en-las-politicas-educativas-la.

Castillo, C. y Raimundo, M. (2012). El 69 platense. Luchas obreras, conflictos estudiantiles y militancia de izquierda en La Plata, Berisso y Ensenada durante la Revolución Argentina. Buenos Aires: Estudios Sociológicos Editora.

Cecchini, D. y Elizalde Leal, A. (2013). La CNU. El terrorismo de Estado antes del golpe. Buenos Aires: Miradas al Sur.

Chaves, G. L. y Lewinger, J. O. (1998): Los del 73. Memoria Montonera. La Plata: De La Campana.

Dawyd, D. (2011). Sindicatos y política en la Argentina del Cordobazo: el peronismo entre la CGT de los Argentinos y la reorganización sindical (1968-1970). Buenos Aires: Pueblo Heredero.

De Riz, L. (2000). La política en suspenso 1966-1976. Buenos Aires: Paidós.

Franzosi, R. (2017). La prensa como fuente de datos socio-históricos: Cuestiones sobre la metodología de recolección de datos a partir de periódicos. Revista de Estudios Maritimos y Sociales, 11, 255-286.

Friedemann, S. (2015). La Universidad Nacional y Popular de Buenos Aires (1973-1974). Una reforma universitaria inconclusa. (Tesis doctoral inédita). Buenos Aires: Sociales-UBA.

Garatte, M. L. (2012). Politicas, grupos académicos y proyectos curriculares de Ciencias de la Educación en la Universidad Nacional de La Plata (1966-1986), (tesis doctoral inédita). Buenos Aires: San Andrés.

Gatica, O. (2005). Lucía. Una historia de militancia y alegría. La vida de una desaparecida. Santa Rosa: edición del autor.

Ghillini, A. y Pis Diez, N. (2017). Universidad, política y revolución entre la Argentina y el Perú: una reconstrucción histórica desde la trayectoria de Jorge Carpio, 1960-1974. e-latina, 61, 21-38. Recuperado de: https://publicac iones.sociales.uba.ar/index.php/elatina/article/view/2469.

Godoy, E. (1995). La historia de ATULP. La Plata: Edulp.

Graciano, O. (2008). Entre la torre de marfil y el compromiso politico. Intelectuales de izquierda en la Argentina. 1918-1955. Bernal: Universidad Nacional de Quilmes.

Gillespie, R. (1987). Soldados de Perón. Los Montoneros. Buenos Aires: Grijalbo.

Halliday, F. (1971). “Estudiantes del mundo, uníos”, en A. Cockburn y R. Blackburn (comps.), Poder estudiantil. Problemas, diagnóstico y acción (pp. 351-399). Caracas: Tiempo Nuevo.

James, D. (1999). Resistencia e integración: el peronismo y la clase trabajadora argentina: 1946-1976. Buenos Aires: Sudamericana.

Katz, S. (2004). Periodismo platense. Génesis y evolución. La Plata.

Lanteri, M. y Talia M. (2015). Bases para la nueva Universidad. La UNLP entre 1973 y 1976. XIJornadas de Sociología, Argentina. Recuperado de: https://cdsa.aacademica.org/000-061/922.pdf.

Lanteri, M. (2009). “Los pasos previos”. El largo proceso de conformación de la JUP en la Universidad Nacional de La Plata (1960-1973). XII Jornadas Interescuelas/Departamentos de Historia, Argentina. Recuperado de: https: //cdsa.aacademica.org/000-008/1039.pdf.

McAdam, D., Tarrow, S. y Tilly, C. (2005). Dinámica de la contienda política. Barcelona: Hacer.

Marín, J. (2009). Cuaderno 8. Buenos Aires: Picaso.

Millán, M. (2020). El movimiento estudiantil y la violencia política en Argentina, 1966-1976. Cuadernos de Marte, $18,89-137$.

Millán, M. (2017). Las movilizaciones estudiantiles en Corrientes y Resistencia durante la "Revolución Argentina", 1966-1973. Folia Histórica del Nordeste, 29, 175-202. Recuperado de: http://doi.org/10.30972/fhn.0292436

Nava, A. (2018). Conflictividad estudiantil, radicalización política y reformismo universitario durante las décadas del sesenta y setenta. El caso del movimiento estudiantil de la ciudad de La Plata 1969-1972. Trabajos y Comunicaciones, 48, 1-30. Recuperado de: e066. https://doi.org/10.24215/23468971e066. 
Nava, A. (2017). Protesta social y conflictividad laboral. Estrategias del movimiento obrero en La Plata, Berisso y Ensenada (1969-1972) (Tesis doctoral inédita). La Plata: UNLP.

Nava, A. (2013). Radicalización y politización del movimiento estudiantil: el caso platense durante la 'Revolución Argentina'. 1966-1972. Revista Conflicto Social, 9, 93-120. Recuperado de: https://publicaciones.sociales.uba.a r/index.php/CS/article/view/255/227.

Nava, A y Romá, P. (2011). Apuntes para el estudio del conflicto obrero - estudiantil en La Plata, Berisso y Ensenada durante las décadas del sesenta y setenta. Revista de Conflicto Social, 5, 256-286. Recuperado de: https://public aciones.sociales.uba.ar/index.php/CS/article/view/379/344.

Panella, C. (2018). El Argentino de La Plata y las elecciones de 1946: democracia vs. dictadura en versión local. Actas de Periodismo y Comunicación, 3, 1-13. Recuperado de: http://sedici.unlp.edu.ar/bitstream/handle/10915/936 36/Documento_completo.pdf-PDFA.pdf?sequence=1\&isAllowed $=\mathrm{y}$.

Pérez Lindo, A. (1985). Universidad, política y sociedad. Buenos Aires: Eudeba.

Piccone, M. (2010). Huellas. Semblanzas de la vida de detenidos-desaparecidos y asesinados por el terrorismo de Estado pertenecientes a la Universidad Nacional de La Plata. La Plata: Edulp.

Pis Diez, N. (2020). Política, universidad y peronismo. Lecturas desde el caso de la FURN de La Plata 1967-1972. Contemporánea, 12, 53-68. Recuperado de: https://ojs.fhce.edu.uy/index.php/cont/article/view/758/637.

Pis Diez, N. (2019). El reformismo universitario, la juventud y la política en los "explosivos" sesentas: el caso del movimiento estudiantil de La Plata en la coyuntura del Cordobazo. Aletheia, 9, 1-13. Recuperado de: http:// www.fahce.unlp.edu.ar/institucional/areas/gestion-editorial-ydifusion/noticias/aletheia-vol-9-num-18-2019.

Pis Diez, N. (2018). Universidad, politica y radicalización en el posperonismo: el caso de la Universidad Nacional de La Plata y su movimiento estudiantil reformista (1955-1966), (tesis doctoral inédita). La Plata: UNLP.

Poulantzas, N. (1971). Poder politico y clases sociales en el Estado capitalista. México: Siglo XXI.

Robles, H. (2011). Radicalización politica y sectores populares en la Argentina de los '70: La juventud peronista y su articulación con Montoneros en los barrios periféricos de la ciudad de La Plata, (tesis de maestría inédita). La Plata: UNLP.

Ramírez, A. J. (1999). Radicalización y peronización de los universitarios. El caso de la UNLP (1969-1974). Sociobistórica Cuadernos del, CISH 4, 189-198.

Romá, P. (2012). Acumulación de capital y conflictividad social en La Plata, Berisso y Ensenada, 1966-1969. En C. Castillo y M. Raimundo (comps.), El 69 platense. Luchas obreras, conflictos estudiantiles y militancia de izquierda en La Plata, Berisso y Ensenada durante la Revolución Argentina (pp. 157-183). Buenos Aires: Estudios Sociológica Editora.

Sarlo, B. (2001). La batalla de las ideas (1943-1973). Buenos Aires: Emecé.

Seoane, M. y Ruiz Núñez, H. (2011). La noche de los lápices. Buenos Aires: Sudamericana.

Sigal, S. (1991). Intelectuales y poder en la década del sesenta. Buenos Aires: Puntosur.

Solari, A. (1968). “Estudiantes y política en América Latina”, en Solari (comp.), Estudiantes ypolítica en América Latina (pp. 7-110). Caracas: Mote Ávila.

Simonetti, M. F. (2002). Tocar el cielo con las manos: La actividad politica de la FURN en UNLP durante 1966-1973, (tesina de grado inédita). La Plata: UNLP.

Suasnábar, C. (2004). Universidad e intelectuales: educación y politica en la Argentina (1955-1976). Buenos Aires: Flacso-Manantial.

Tarrow, S. (1997). El poder en movimiento. Los movimientos sociales, la política y la acción colectiva. Madrid: Alianza.

Tilly, Ch. (2006). Regimes and repertoires. Chicago: UCP.

Tortti, C. (2000). Protesta social y “nueva izquierda” en la Argentina del “Gran Acuerdo Nacional”. En H. Camarero y P. Pozzi (comps.), De la revolución libertadora al menemismo. Historia social y politica argentina (pp. 129-154). Buenos Aires: Imago Mundi. 


\section{Notas}

1 ]Dada la oposición de El Día a Montoneros podemos suponer que el periódico no omite las acciones contenciosas en la Universidad que fundamentan su línea editorial y su interés en excluir a tales agrupaciones de la UNLP. Por ello no sospechamos de un problema de validez cuando el registro de la fuente arroja una merma en la conflictividad durante el tercer peronismo.

2 "El ala radicalizada del peronismo cedió posiciones, a expensas de los sectores del radicalismo y la izquierda", en $L a$ Opinión, 8/10/1974, año IV, n 1.019 , p. 14.

3 "Franja Morada perdió la conducción de la regional universitaria de La Plata", en La Opinión, 7/12/1974, año IV, n 1.065 , p. 11. 